\title{
Discrepancies Not Only in Physicians, But Also in Atrial Fibrillation Guidelines
}

Atrial fibrillation (AF) is an established risk factor for a first or recurrent stroke. ${ }^{[1]}$ The advent of direct oral anticoagulants (OACs) has resulted in a choice of therapeutic agents for stroke prevention in patients with $\mathrm{AF}$ in addition to Vitamin $\mathrm{K}$ antagonists (VKA). Although there are many recommendations of different societies such as American College of Cardiology/American Heart Association/Heart Rhythm Society (AHA/ACC/HRS), European Society of Cardiology (ESC), and Canadian Cardiovascular Society AF guidelines, there are important differences among them. Specifically, major differences can be observed in the nomenclature of OACs, the definition of nonvalvular AF (NVAF), the stroke risk stratification algorithm used to determine criteria for oral anticoagulant therapy, and the role of acetylsalicylic acid (ASA) in stroke prevention in $\mathrm{AF}$.

In this issue of the journal, Sanliap et al. ${ }^{[2]}$ published an interesting web-based survey regarding possible discrepancies on perception and management strategies of AF expressed by Turkish physicians.

Various terms have been used to describe the "new" class of OACs. The International Society on Thrombosis on Haemostasis suggests using the term "direct oral anticoagulant [DOAC]" to this treatment that directly inhibits a single target and has clinical properties (dabigatran, rivaroxaban, apixaban, edoxaban, and betrixaban) based on a web-based survey which includes 16 thrombosis, hemostasis, anticoagulation, and vascular medicine societies from North America and Europe (total 150 participants). ${ }^{[3]}$ However, ESC prefers non-VKA OACs (NOACs) which is currently the main term used by the much larger community of cardiologists. ${ }^{[4]}$

Beyond the nomenclature, there are important differences in the definition of NVAF. In 2018, the European Heart Rhythm Association suggested a novel classification for NVAF. ${ }^{[5]}$ According to this guide, Evaluated Heart valves, Rheumatic or Artificial (EHRA) categorization is proposed, depending on the type of OAC use in patients with AF. EHRA Type 1 refers to $\mathrm{AF}$ patients with valvular heart disease (VHD) needing therapy with a VKA, including in particular moderate-severe mitral stenosis of rheumatic origin and mechanical prosthetic valve replacement. In contrast, EHRA Type 2 VHD refers to VHD patients needing thromboembolic prevention therapy for AF with a VKA or a NOAC, including essentially all other native valvular stenoses and insufficiencies as well as mitral valve repair, bioprosthetic valve replacements, and transaortic valve intervention.
In 2019, update of $2014 \mathrm{AHA} / \mathrm{ACC} / \mathrm{HRS} \mathrm{AF}$ guideline states VHD more narrowly as moderate-to-severe mitral stenosis (any etiology) or mechanical heart valve. ${ }^{[6]}$

Interestingly, although there are no specific statements about any valve regurgitation in guidelines, Sanliap et al. ${ }^{[2]}$ found that $36 \%$ of participants evaluated mitral regurgitation as valvular AF.

For stroke risk prediction, guidelines use the $\mathrm{CHA}_{2} \mathrm{DS}_{2}-\mathrm{VAS}_{\mathrm{c}}$ score. ${ }^{[6,7]}$ Although the ESC was first to adopt $\mathrm{CHA}_{2} \mathrm{DS}_{2}-\mathrm{VAS}_{\mathrm{c}}$ score, in 2016, the ESC guideline modified the criteria of female sex as an independent risk factor, perceiving that "female sex does not appear to increase stroke risk in the absence of other stroke risk factors." In line with the ESC, recent AHA/ACC/HRS guideline changed previous suggestions to female sex, if the only risk factor, does not confer a $\mathrm{CHA}_{2} \mathrm{DS}_{2}-\mathrm{VAS}_{\mathrm{c}}$ score of 1 . Female sex adds to the score only when another risk factor is present. ${ }^{[6]}$ Both guidelines recommend to use OACs for patients with $\mathrm{AF}$ and $\mathrm{CHA}_{2} \mathrm{DS}_{2}-\mathrm{VAS}_{\mathrm{c}}$ score of 2 or greater in male or 3 or greater in women (Class 1 recommendation). However, there is a discrepancy between two guidelines to use OAC for patients with $\mathrm{AF}$ and $\mathrm{CHA}_{2} \mathrm{DS}_{2}-\mathrm{VAS}_{\mathrm{c}}$ score of 1 in male or 2 in women. While the ESC makes a Class 2a recommendation for these groups, according to the recent AHA/ACC/HRS guideline, $\mathrm{OAC}$ use might be reasonable (Class $2 \mathrm{~b}$ recommendation).

The ESC has entirely eliminated ASA from their guidelines in 2016. Similarly, the current AHA/ACC/HRS guideline does not recommend ASA for patients with low $\mathrm{CHA}_{2} \mathrm{DS}_{2}-\mathrm{VAS}_{\mathrm{c}}$ score. When OAC is indicated, a preference for DOAC over VKAs is expressed by both AHA/ACC/HRS and ESC (Class 1 recommendation). ${ }^{[6,7]}$

Sanliap et al. ${ }^{[2]}$ reported in their survey that $63 \%$ of physicians preferred to use OACs in AF patients with $\mathrm{CHA}_{2} \mathrm{DS}_{2}-\mathrm{VAS}_{\mathrm{c}}$ score of 1 in male or 2 in women. In addition, $21 \%$ of them prescribed ASA (answers from question 10). Nevertheless, $71 \%$ of physicians set $\mathrm{CHA}_{2} \mathrm{DS}_{2}-\mathrm{VAS}_{\mathrm{c}}$ score 2 or greater as the limit to start OAC therapy in a female patient with $\mathrm{AF}$ (answer from question 17). Because question 10 and 17 interrogated the knowledge of AHA/ACC/HRS and ESC guidelines, respectively, these findings support the discrepancies of them.

Another finding from the survey was $26 \%$ of the physicians preferred ASA in older patients. In furtherance, $21 \%$ of participants did not prefer to use $\mathrm{OAC}$ in geriatric population and concomitant risks (e.g., risk of falling). However, falling risk should not be an exclusion criterion to anticoagulant since 
older patients are at an increased risk of stroke and have been shown to benefit from OAC. ${ }^{[5]}$

In conclusion, in spite of the small number of participants, this present study represents a nice addition to a growing body of evidence how they were perceived by Turkish physicians. The contemporary management of AF continues to evolve as the new trials and guidelines are published. Because of inadequate findings for specific subgroups/conditions, we need more data from well-designed studies for the potential use of these therapeutic agents in AF.

Gonenc Kocabay

Department of Gerontology, Faculty of Health Science, Istanbul University-Cerrahpasa, Istanbul, Turkey

ORCID:

Gonenc Kocabay: https://orcid.org/0000-0002-1439-0252

Address for correspondence: Dr. Gonenc Kocabay, Department of Gerontology, Faculty of Health Science, Istanbul University-Cerrahpasa, Istanbul, Turkey.

E-mail:kocabay@gmail.com

\section{REFERENCES}

1. Hammersley D, Signy M. Navigating the choice of oral anticoagulation therapy for atrial fibrillation in the NOAC era. Ther Adv Chronic Dis 2017;8:165-76.

2. Sanliap SC, Turk UO, Okyay K, Basaran O, Canpolat U, Zoghi M. Differences in Atrial Fibrillation Management Strategies among Physicians: A Survey Based Study. Int J Cardiovasc Acad 2019;5:53-60.

3. Barnes GD, Ageno W, Ansell J, Kaatz S; Subcommittee on the Control of Anticoagulation of the International Society on Thrombosis and Haemostasis. Recommendation on the nomenclature for oral anticoagulants: Communication from the SSC of the ISTH. J Thromb Haemost 2015;13:1154-6.

4. Husted S, Lip GY, De Caterina R. Recommendation on the nomenclature for oral anticoagulants: Communication from the SSC of the ISTH: Comment. J Thromb Haemost 2015;13:2130-2.

5. Steffel J, Verhamme P, Potpara TS, Albaladejo P, Antz M, Desteghe L, et al. The 2018 European Heart Rhythm Association practical guide on the use of non-Vitamin $\mathrm{K}$ antagonist oral anticoagulants in patients with atrial fibrillation. Eur Heart J 2018;39:1330-93.

6. January CT, Wann LS, Calkins H, Chen LY, Cigarroa JE, Cleveland JC Jr., et al. 2019 AHA/ACC/HRS focused update of the $2014 \mathrm{AHA} / \mathrm{ACC} / \mathrm{HRS}$ guideline for the management of patients with atrial fibrillation: A report of the American College of Cardiology/American Heart Association task force on clinical practice guidelines and the Heart Rhythm Society. J Am Coll Cardiol 2019. pii: S0735-1097(19)30209-8.

7. Kirchhof P, Benussi S, Kotecha D, Ahlsson A, Atar D, Casadei B, et al. 2016 ESC Guidelines for the management of atrial fibrillation developed in collaboration with EACTS. Europace 2016;18:1609-78.

This is an open access journal, and articles are distributed under the terms of the Creative Commons Attribution-NonCommercial-ShareAlike 4.0 License, which allows others to remix, tweak, and build upon the work non-commercially, as long as appropriate credit is given and the new creations are licensed under the identical terms.

\begin{tabular}{l|l}
\hline Submission: 13-Feb-19 Revision: 16-Feb-19 Accepted: 18-Feb-19 \\
Access this article online \\
\hline Quick Response Code: & Website: \\
& \\
\end{tabular}

How to cite this article: Kocabay G. Discrepancies not only in physicians, but also in atrial fibrillation guidelines. Int J Cardiovasc Acad 2019;5:66-7. 